Este trabalho tem como objeto de estudo um colégio que deslocou funções do professor e do livro para novas posições, por meio de um método de ensino programado. Analisam-se os efeitos de exclusão do saber nessa prática de pulverização, que fragmenta a função paterna de organizar e transmitir o saber.

Pedagogia e psicanálise; métodos pedagógicos; o saber entre pedagogias

\section{THE EXCLUSION OF KNOWLEDGE}

This paper focuses on a school that displaced teacher's and book's functions to new positions, through a programmed teaching method. It analyses the effects on the knowledge exclusion of this pulverization praxis that fragments father's function, the function that organizes and transmits knowledge. Knowledge; exclusion; psychoanalysis

\section{A EXCLUSÃO DO SABER}

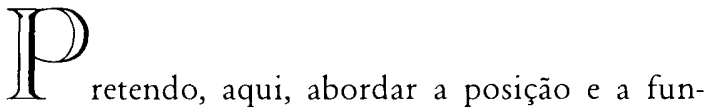
ção do saber a partir de um estudo que realizei há alguns anos, ao interrogar o modo de funcionamento de um Colégio. Não pude, naquela ocasião, articular os registros colhidos de entrevistas com alguns profissionais do Colégio, devido a minha própria dificuldade em transpor o registro do que ali ouvi. A dívida com os agentes individuais da instituição, $e$, ainda, com a própria instituição que inicialmente me solicitou o estudo, conduziu a contingência de equacionar os efeitos dos agentes que me acolheram e que se dispuseram a articular suas idéias sobre as modalidades pelas quais essa instituição escolar trata os sujeitos que aprendem e que ensinam.

$O$ estudo de caso tem questões e formulações ainda precárias. Entretanto, aposto que a possibilidade de partilhá-las com outros educadores, e com outros psicanalistas, pode permitir o surgimento de novas hipóteses de trabalho.

A especificidade desse Colégio exige considerar o fator nostálgico em que ele tende a esbarrar. Se podemos, por um lado, simplesmente, descartar a prática educativa dessa instituição, considerando nela somente o ensino massificado que opera a degradação de valores conquistados na modernidade, e referindo-a a mero subproduto da ditadura brasileira; por outro lado, talvez possamos levar a sério a hipótese de que, a despeito de suas origens e das

Psicanalista, doutora em Psicologia Clínica pela PUC-SP, membro da equipe técnica da Derdic da PUC-SP. 
modalidades do empreendimento econômico posto em jogo na formação dessa escola, ela transita em um mundo que é enigmático para a geração que a precede. Os comentários de um artigo jornalístico brasileiro, escrito por Calligaris (1996), convidam a rever essa nostalgia. O autor lembra-nos que hoje somos imigrantes recém-chegados ao estrangeiro, ao mesmo território que é a pátria das crianças. Elas sabem a língua, hábitos e códigos do novo mundo e podem nos conduzir na exploração do que é, para nós, uma terra incógnita: "[...] a nova geração, treinada na leitura rápida da linguagem icônica e reduzida aos quadrinhos, talvez tenha elaborado, ou darwinianamente produzido, uma capacidade de leitura das imagens muito mais rápida do que a nossa. Por isso, ela não se satisfaria com a contemplação passiva de um programa de televisão, preferindo o ritmo da MTV ou então surfando na massa de informação proposta pela TV, de imagem em imagem. Ela não é pouco atenta ou incapaz de concentração, mas possuiria um tipo próprio de concentração, que corresponde adequadamente à circulação de informação de nossos tempos. Enfim, a Internet [...] é de fato o lugar virtual onde aos poucos vem se reconstituindo uma comunidade perdida e a globalização não é só um projeto eletrônico multinacional"'.

Minha hipótese é que a prática desse Colégio antecipa e demonstra uma das modalidades pelas quais o declínio da função paterna - ou simbólica - é operado na atualidade escolar. Isso porque essa prática parece interrogar a condição do saber, ou seja, a possibilidade de um sujeito ultrapassar a identificação imaginária à consistência de sentidos de elementos da linguagem, por meio do recurso às demarcações simbólicas do laço social que os reduz, de modo que esse sujeito possa constituir a sintaxe à qual ele se refira e que o oriente, conquistando, assim, um lugar em que circule na linguagem ao mesmo tempo em que dela se diferencia. Enfim, a hipótese é que a condição do saber é tratada, nessa prática pedagógica, com operações de mediação que interceptam a relação entre o saber e a constrição simbólica necessária ao sujeito.

Cabe entretanto frisar que tal hipótese localiza-se aquém de uma crítica nostálgica, pretendendo, apenas, distinguir os operadores acionados nas condições atuais e que the dão suas condições de possibilidade. Por isso, antes de dar início à abordagem do sistema de ensino calcado no método educativo de ensino programado desse Colégio, é necessário interrogar o que se concebe como aprender e os princípios que o regem nas contingências atuais. Destaca-se, no estudo de caso que considero aqui, uma distinção relativa à psicologização da pedagogia, tão comum à maioria das escolas progressistas, em que a focalização da individualidade do aluno 
torna-se um imperativo intenso o suficiente para produzir um excesso narcísico impeditivo da submissão às regulações do laço social. A alienação da pedagogia encontra, aqui, seu reverso. Infelizmente, isso não implica um confronto entre perspectivas, mas tão-somente uma polarização que situa seus princípios numa oposição que os distingue, embora, ao mesmo tempo, produzindo uma similaridade que os põe em relação de identidade, tornando-os, portanto, reversíveis um ao outro.

Essa escola nos coloca, sem intermediação, diante do profundo mal-estar que a educação brasileira refletida nas crianças nos causa atualmente, e que Calligaris (1996) formula com as seguintes palavras: "Afinal, há mesmo uma oposição misteriosa entre uma geração de pais que, em geral, foram teenagers nos anos $60 \mathrm{e}$ querem se considerar progressistas e abertos, e uma geração de 'screenagers' que encontra, vindo de seus pais, um desprezo sistemático e inexplicado por sua cultura". Talvez tenhamos que considerar a hipótese de que o mundo que nos espreita não é regido pelos valores que supúnhamos essenciais: "[...] Tocar o futuro significa também acreditar na diferença de nossas crianças, não liquidá-las de antemão como um extravio, mas admitir por um instante que elas possam ser reconhecidas como a difícil invenção de maneiras de viver em um mundo novo, em que certamente nossa palavra não os guia" (Calligaris, 1996). Cabe interrogar, portanto, como essa suposta oposição entre uma pedagogia psicologizante progressista e uma pedagogia alienadora retrógrada pode ser circular e, enfim, produzir simetria.

Para avançar na tentativa de bordejar a especificidade metodológica da escola em pauta, fiz algumas entrevistas com professores, orientadores educacionais, coordenadores e construtores da proposta pedagógica. A continuidade do projeto foi proposta por meio de entrevistas com uma amostra verdadeiramente significativa de pessoas nos diversos níveis em que a metodologia educacional tem vigência: professores, orientadores, alunos e seus pais, a partir dos aspectos ressaltados nas entrevistas de sondagem realizadas. Pretendia, ainda, assistir às aulas e participar das demais atividades do Colégio. Entretanto, essa continuidade mostrou-se inviável.

Portanto, as considerações que se seguem restringem-se ao período de sondagem para uma pesquisa e não devem ser consideradas conclusivas. Trata-se, apenas, de um primeiro esboço da tentativa de delimitar o método educativo desenvolvido numa escola brasileira, interrogando, ao mesmo tempo, o modo como essa instituição concebe e trata o laço educativo.

\section{O COLÉGIO E SEUS IDEAIS}

O Colégio, constituído nos últimos trinta anos, desenvolve um projeto ao mesmo tempo empresarial e educacional, que visa a dar plena vigência aos eixos metodológicos 
construídos num curso preparatório que obtivera grandes índices de aprovação no vestibular. Assim, além de oferecer, desde as classes primárias, as condições tidas como mais adequadas para o ingresso dos alunos na Universidade, pretende, também, acolher o imaginário juvenil.

Os pilares do método educativo foram edificados nessa perspectiva. Seu princípio básico foi idealizado para dar orientação a uma escola em permanente interatividade com os alunos, fundada nas expectativas deles, e capaz de permitir que os jovens nela se reconhecessem. Tendências preponderantes recolhidas de falas infantojuvenis informaram propriedades correlativas desse princípio.

Assim, a antecipação do futuro e a preservação da natureza estruturaram a base do cotidiano escolar. Essas propriedades inseriram-se, como lógicas da escola, nessas duas vertentes. Tecnologia e ecologia inscreveram-se nos atos educativos como traços que ultrapassavam os horizontes formalizados pela sala de aula, por meio de projetos diversos.

No que tange à tecnologia, diferentes níveis de vivência em laboratórios de aprendizagem tinham por objetivo promover interações imediatas e de grande amplitude. A escola adotou computadores de várias gerações, que, em patamares diversos, permitem o conhecimento de seu funcionamento e sua utilização quotidiana. $\mathrm{O}$ Clube do Futuro passou a debater o impacto da tecnologia na vida da humanidade. O estudo de várias disciplinas é complementado com videodiscos a laser, reproduzindo fatos históricos ou condições geográficas; a videoaula permitiu a apresentação de eventos do quotidiano em forma jornalística, precedendo seu aprofundamento pelos professores. Um teatro-laboratório contemplou as possibilidades mais arrojadas de multimídia, associando tecnologia, arte, educação e pesquisa, e nele as situações mais diversas (como andar em solo lunar) eram simuladas ou criadas (por meio de filmes e desenhos animados). Com o Projeto Ensat, especialistas convidados deram aulas sobre temas atuais, via satélite, para os alunos, que podiam formular questões e serem ouvidos por todo o Brasil, até que vídeos os substituíram, formando um banco de dados à disposição permanente para alunos e professores.

A ecologia foi acrescentada ao currículo como disciplina, sendo apresentada por meio de cursos em campi avançados, em que a natureza passou a servir de laboratório e à criação de situações de aprendizagem que permitiram, ainda, a interação escola-comunidade. O Projeto Paranoá (em Brasília, desde 1988), a Escola do Mar (em Angra dos Reis, desde 1988), a Escola da Natureza (na Amazônia, desde 1989) e a Escola de Dunas (em Natal, desde 1990) compuseram, juntos, essa rede. Em cursos de fins de semana ou sema- 
nais, alunos de todo o Brasil realizam estudos de campo contando com diversos recursos tecnológicos (princípios de biologia marinha e oceanografia, ecologia, navegação, pesca, mergulho, meteorologia, estabelecimento de níveis de poluição, fauna, flora, exame de áreas de desmatamento, reconhecimento da situação atual de culturas locais), assistem ao cultivo de frutos do mar em fazendas marinhas e atuam para ajudar populações locais na preservação ambiental e orientar sobre riscos de contaminação.

Além do enfoque aos eixos acima apontados, uma rede de atividades foi acrescida às atividades escolares obrigatórias, funcionando, na escola, a partir dos interesses específicos dos alunos avaliados acima da média, ultrapassando ou aprimorando o trabalho ali promovido: a programação avançada abrange estudos aprofundados (de física nuclear, computação, biologia molecular, etc.), conforme a área de interesse de alunos dos dois primeiros anos do $2^{\circ}$ Grau; o laboratório de redação capacita alunos para a leitura e interpretação de textos; a programação paralela contempla alunos do $3^{\circ}$ ano com bom desempenho, que demandam o aprofundamento de temas específicos exigidos nos exames vestibulares; o plantão de dúvidas mantém permanentemente professores à disposição de alunos para esclarecimentos e orientações pessoalmente ou por telefone; as atividades esportivas ultrapassam as aulas normais de educação física, desenvolvendo treinamentos, aulas específicas de cada esporte e competições diversas; as várias atividades culturais e recreativas são realizadas por meio de cursos, gincanas, viagens e visitas culturais; a oficina literária e de artes cênicas, a galeria de arte para exposição de trabalhos, o festival interno de música e a possibilidade da montagem de espetáculos estão à disposição dos alunos, de acordo com a flutuação de seus interesses.

Pode-se reconhecer, nas palavras de seu maior idealizador, o ideal de escola proposto pelo Colégio: "A escola pode ser um canto livre em que, ao aprender, os alunos tenham brilho nos olhos e sorriso nos lábios. Isso pode acontecer sem nenhuma receita vanguardeira ou poção milagrosa. Apenas com a redescoberta silenciosa de que o saber fossilizado não aguça curiosidade intelectual alguma. Crianças e jovens entediam-se com facilidade. Porque o mundo deles tem a dinâmica de nossa contemporaneidade acelerada e multiforme. Não adianta forçá-los a decorar fórmulas e dados, se a televisão tem cores animadas e a vibração dos eventos que se sucedem em ininterrupta mutação. [...] Transmitir saber não é uma celebração cerimonial, mas um processo dinâmico, que deve remeter à realidade na qual os alunos estão mergulhados. Por isso a necessidade imperiosa das atividades laboratoriais, informadas pela teoria. A tecnologia contemporânea não deve ser uma caixa-preta, mas a porta de entrada dos alunos no mundo que é deles. É possível aprender fazendo, brincando, experimentando. Mas, para tanto, é preciso antes que os professores e especialistas da Educação se disponham a encarar a realidade cotidiana como capítulo legítimo do conteúdo curricular” (Di Genio, 1987, p. 18). 
O exercício desse funcionamento gerou alguns trabalhos reflexivos sobre as práticas produzidas. Algumas das atividades escolares foram tratadas por meio de estudos que apresentam as inovações educacionais do Colégio ${ }^{2}$, permitindo constatar que algumas das atividades especiais adquirem níveis de excelência. Entretanto, os estudos sobre o quotidiano escolar mantêm a posição de refletores: sem tornar as atividades da escola alvo de problematização, limitamse a divulgar as realizações que tais ideais alicerçam, constatando sua eficácia.

\section{A ESTRUTURA DE FUNCIONAMENTO DO COLÉGIO}

A especificidade da prática escolar quotidiana do Colégio, em sala de aula, não foi contemplada por uma análise que distinguisse suas propriedades. Afinal, enquanto as atividades especiais foram enaltecidas, o eixo maciço da aprendizagem formal em sala de aula não foi efetivamente problematizado. Trata-se do material didático que permeia e dá sistematicidade a cada disciplina no $1^{\circ}$ e no $2^{\circ}$ Grau: o ensino programado, viabilizado por meio de apostilas atuais Cadernos de atividades - produzidas por uma pequena equipe de professores do próprio Colégio, que, em geral, estiveram presentes desde os seus primórdios.

Essa metodologia remonta ao início da constituição do Colégio, que respondeu às contingências do sistema educacional brasileiro, em especial no que se refere ao processo de acesso à Universidade. As diferenças dos conteúdos enfocados e exigidos para aprovação nas disciplinas dos colégios e as exigências das provas seletivas às universidades criaram a urgência de cursos preparatórios para as provas vestibulares, de modo que fossem revistos, atualizados, aprofundados e ensinados conteúdos nunca antes fornecidos aos alunos candidatos aos diversos cursos universitários.

Alguns complicadores impunham-se a essa tarefa. A premência da aquisição do conhecimento era fato inexorável. Entre a conclusão nos cursos médios, que liberavam o aluno das exigências escolares (tornando-o apto ao vestibular), e o próprio vestibular, havia um tempo mínimo para a dedicação específica ao estudo dos conteúdos desconhecidos e exigidos na provas vestibulares. A defasagem entre o saber universitário e o saber do aluno que havia concluído o ensino médio fazia-se evidente na ausência de livros propriamente didáticos que abarcassem os conteúdos exigidos, tornando necessária 
a figura de professores que se dispusessem a funcionar como livros vivos. Assim, os professores ditavam as aulas e os alunos as copiavam, transformando o processo de transmissão de conhecimentos em sala de aula num procedimento de acumulação de registros escritos: "Ele ditava as aulas. Todo um curso enorme, os alunos ficavam copiando que nem loucos, era uma loucura total para copiar as aulas";; "A história toda é que, antigamente, os professores simplesmente ditavam aula. [...] Não existia apostila, não existia nada, não existia indicação de livro, nada, nada, nada. Simplesmente o professor ditava a matéria, os alunos copiavam como uns loucos, copiavam tudo simplesmente para ter alguma coisa sobre a qual estudar. Porque as questões eram muito dificeis, que não se encontravam muitas vezes em compêndios de livros. Não dava para o professor dizer: eu indico tal livro" 4 .

Nessas condições, alguns professores registraram o conteúdo exigido em apostilas, ao mesmo tempo em que desenvolveram habilidades para fisgar e sustentar a atenção dos alunos aos conteúdos objetivados, muitas vezes acrescidos de recursos mnemônicos diversos, em que versos, músicas e chistes transpunham as exigências de raciocínio. A fama de tais habilidades fez história. Não é por acaso que um recente artigo jornalístico faz referência à habilidade do principal fundador do Colégio, hoje proprietário da maior universidade do país, nos seguintes termos: "O talento didático e a oratória entusiasmada renderam-lhe classes lotadas" (Oyama \& Manso, 1999, pp. 92-8).

\section{A APOSTILA}

A metodologia de ensino programado indica uma série de interrogações que delimitam um campo da investigação. $O$ acesso direto do aluno aos livros foi abandonado e substituído pelo material didático produzido pelos professores e impresso nos Cadernos de atividades dos alunos. Considerando-se o ideal em que a escola se edificou, o que teria promovido essa transposição do livro?

$\mathrm{Se}$, inicialmente, os professores funcionavam como livros viVOS, a transformação dos registros escritos em aprendizagem passível de suportar as exigências de provas de avaliação de conhecimentos, entretanto, deixava a desejar, quando o método foi transposto do curso pré-vestibular ao colégio. Era preciso distinguir e otimizar, no processo de produção da aprendizagem, as condições dos alunos, a função do professor e o papel do material didático, 
na perspectiva da construção da possibilidade de transmitir o conhecimento, entrelaçando, pela via da escola, o professor e o aluno. "Na própria física, o ensino até aquela época era muito teórico, matemático, difićlimo, baseado em livros que não eram nada didáticos [...]. Na própria física o dr. Di Genio entrou com um outro método de ensinar, um método prático, bem objetivo mesmo [...] Então esse método do Di Genio ensinar física lhe deu muita fama nesse tempo, os alunos adoravam o Di Genio, eles estavam aprendendo física mesmo, era mais prático, entende. [...] bem objetivo mesmo. Então, praticamente, foi uma revolução no método de ensinar física mesmo".

Vários professores desenvolveram habilidades específicas para a transmissão de conhecimentos, mobilizando a singularidade de seus estilos particulares: imediaticidade na aprendizagem; praticidade; capacidade de sintetizar conteúdos em poesias, músicas, piadas e esquemas gráficos, tornando-se, muitas vezes, verdadeiros atores da cena da transmissão do conhecimento, tornada assim um espetáculo. Esses professores acabavam sendo negociados a preço de ouro entre os diversos cursos preparatórios: "Naquele tempo, apareceu o Cescem, Centro de Seleção para Candidatos das Escolas Médicas; o Cescea, para a área de humanas, e o Mapofei, para exatas. E o Cescem começou a pedir alguns assuntos de química que não eram dados nos colégios, até aquela época. Não era química nova não, era química que não era dada. [...] Praticamente eu era o rei do assunto nessa época. [...] Para você ter uma idéia, eu ganhava 3 mil cruzeiros por aula no Brigadeiro, e ele me pagou 20 mil"'6.

A produção de apostilas do Colégio é ato de crítica ao material didático tradicional, capaz de justificar tal empacotamento. Essa crítica apóia-se nas contradições, equívocos, inadequação da linguagem, dificuldade de acesso a conhecimentos esparsos de livros distintos ou mesmo na falta de atualização destes. Enfim, as apostilas simplificaram, condensaram, resumiram livros e, portanto, permitiriam prescindir dos livros e dos seus autores, tornando público o saber antes restrito a uma elite. Mas cabe perguntar: teriam elas produzido, em contrapartida, um ensino simplificado no qual o aluno e o professor deixariam de encontrar lacunas e assim não teriam que se submeter à mobilização de esforço para "resolver" a defasagem entre o "saber oficial" e a realidade quotidiana, deixando de lado o acesso às nuanças e às diferenças conceituais que uma bibliografia permitiria enquanto promotora de comparação sistemática?

A metodologia de ensino, desenvolvida inicialmente no Curso prévestibular, permitiu sua expansão para as áreas práticas ou laboratoriais de cada disciplina, e para os outros níveis escolares. Nos seus trinta anos de funcionamento, o Colégio, criado em 1971, estendeu-se por todo o Brasil (diretamente ou por convênios com instituições educativas locais), mantendo o mesmo eixo metodológico de transmissão do currículo oficial, capaz de abarcar o ensino de uma grande população de escolares. 
Tal sistema metodológico foi construído como o mais importante braço do Colégio que se integra na mesma perspectiva do ideal educacional já salientado. O sistema programado de ensino mantém um conteúdo programático em que os exercícios e as provas correspondentes a cada disciplina, previamente estabelecidos aula por aula, dia a dia, são cumpridos, em todas as unidades, ao mesmo tempo. Esse sistema é apresentado na agenda fornecida a todos os alunos, informando-lhes o plano geral de seus compromissos anuais: aulas, provas, sistemas gerais de avaliação, além das regras disciplinares da escola. O sistema é viabilizado por meio do material didático construído por uma elite de professores de cada uma das disciplinas, contemplando os conteúdos básicos e os exercícios de fixação de cada disciplina, em cada dia do ano letivo, nas onze séries escolares do $1^{\circ} \mathrm{e}$ do $2^{\circ}$ Grau, para os mais de 300 mil alunos em todo o país. Um parque gráfico de última geração atualiza sistematicamente os Cadernos de atividades, e garante sua remessa a tempo para todo o Brasil, mantendo o funcionamento de um sistema absolutamente autônomo.

As apostilas informam ao aluno aquilo que lhe é imprescindivel saber circular. O eixo duro do conhecimento exigido em cada período escolar fica assim explicitado: o essencial a saber. Estabelece-se uma relação em que a exigência escolar é nítida, está livre dos atravessamentos imaginários que tantas vezes são impostos como labirintos na relação professoraluno. A deriva, que por vezes enre- 
da o aluno, é contida pela apostila, uma vez que ela formula, objetivamente, o que lhe será exigido. Entretanto, ela também permite levantar a questão: todas as atividades paralelas que são sobrepostas a esse eixo não denunciariam a própria insuficiência do método de ensino programado?

\section{O PROFESSOR}

Outra função estruturante do Colégio é a do professor. Podese observar uma grande diferença entre a concepção dos professores que são, ao mesmo tempo, produtores das apostilas e aqueles que tão-somente funcionam como transmissores. No primeiro grupo, os professores salientam que a apostila funciona como uma instância reguladora que cria um terceiro elemento produtor de uma nova circulação na relação professor-aluno: "De acordo com a dinâmica do professor, ele consegue cumprir aquilo e fazer o aluno pensar. Agora, depende do professor, da experiência dele, do conhecimento também. Porque tem professores que são mais fluentes, outros não são tanto" ", "Os professores tentam mesmo, em cada conceito, fazer os alunos raciocinarem sobre os conceitos, e depois a prática, os exercícios, para firmar, fixar mesmo. Então, toda aula não fica sem exercício, praticamente isso é como se fosse uma lei"

Por outro lado, os professores entrevistados que não são construtores das apostilas referem-se a sua função com o nome de animador de classe. E é assim que um deles se nomeia: "Venho aqui apresentar espetáculo, sou um animador de classe"; "Talvez eu ganhasse melhor como artista da Globo, mas minha função é mesmo a de fazer teatro, manter todo o mundo atento, representar um papel" ${ }^{10}$.

A imperatividade dessa metodologia deslocou o exercício da função do professor e reconfigurou a relação professor-aluno. $O$ professor foi destituído do poder decisório sobre o que e quando deve ensinar. O saber não é do professor, mas está impresso numa apostila elaborada pelos verdadeiros detentores do saber. $\mathrm{O}$ professor faz então a função antes delegada ao livro: ele se torna mediador entre o saber da apostila e o aluno. Ambos, professor e aluno, submetemse plenamente a ela. Se o professor se mantém como garante da relação entre o aluno e o saber, ele não é mais o detentor do saber, não o faz incidir com seus próprios motivos psíquicos e ideológicos. A especialidade do método de ensino programado arranca a vulnerabilidade do aluno à personificação do saber em um professor. 
Nessa perspectiva, as concepções sobre a importância do laço identificatório do aluno ao professor (e vice-versa) são abandonadas. A intermediação de um material didático ao mesmo tempo suficiente (por sua alta qualidade e por seus passos criteriosos, como dizem seus autores, sem precisar de qualquer sancionamento exterior ao sistema), obrigatório e definitivo para professor e aluno se impõe ao que, nas teorias relativas à aprendizagem, sustenta a posição de aluno relativamente ao mestre, permitindo excluir da esfera escolar o campo da inclusão dos sujeitos e de suas paixões singulares. Enfim, pode-se perguntar, a proposta educacional voltada para a experiência, a interatividade e a criatividade poderia sustentar-se num método que pressupõe a autonomia do aluno para aprender, contemplado pela pressa proposta na relação biunívoca entre conteúdo a adquirir e cronometria de aquisição? Poder-se-ia considerar que a embreagem do campo dos afetos, considerada pela via da pedagogia progressista como função primordial do professor e tida muitas vezes em valência superior ao domínio do conteúdo a ser ensinado, seria superada nessa proposta (ou no mínimo reservada a certos campos do conhecimento em que o Colégio apenas mantém a possibilidade de fazer suplência na medida da demanda dos alunos)?

Há que se considerar que a metodologia inaugurada pelo Colégio ultrapassa muito a perspectiva de um aperfeiçoamento. Trata-se de um pulo metodológico que desvincula completamente a escola de uma extensão da vida doméstica e privada. Trabalha-se com uma outra concepção de escola cuja função não é mais garantir ou suprir os vínculos do aluno à tradição, à cultura ou à família, mas aparelhar instrumentalmente a criança $e$ o adolescente para detectar as urgências na realidade, através de um modo de transmissão do que se considera imprescindível saber, obedecendo ao meio em que eles circulam.

Mas cabe ressaltar um fator que talvez não seja negligenciável: os professores que construíram as apostilas salientam o valor que lhes era atribuído no campo educacional, a ponto de torná-los alvos de disputas entre instituições educacionais diversas: "Antigamente o professor tinha que fazer a sua programação, tinha que ficar bolando. Agora, isso é dado de mão beijada para ele, tá tudo pronto. Cabe a ele, agora, dinamizar, descobrir o modo de reter o envolvimento do aluno" "1. Interessa notar que a especificidade e a singularidade de métodos pessoais de ensinar fazia deles professores especiais para os alunos e disputados pelas escolas. Com esse valor capital, acrescido às condições econômicas e políticas de alguns de seus autores e aos fatores educacionais da época, foi possível construir um método que os perpetua e os enaltece, impedindo a possibilidade de os atuais professores do Colégio também se destacarem pela mesma singularidade. Afinal, o que a metodologia em pauta propõe é que o professor apenas faça valer o saber que pertence ao Colégio, e reduza sua função à representação da cena em que o saber da apostila é colado ao aluno: "O professor, antes, ele 
podia inclusive ficar dez aulas num assunto, agora tem a cobrança do próprio aluno que sabe o que ele tem que dar [...] ele é obrigado a dar toda a matéria"12.

Nessa perspectiva, várias formalidades tradicionais entre professor $e$ aluno foram destituídas ou implementadas num novo registro. O professor não faz a chamada que confere a presença dos alunos em classe; o professor não elabora nem sabe a quem se deve a manifestação de um aluno nas provas de avaliação, já que essas provas estão distinguidas apenas pelo número do aluno e não por seu nome: "O Caderno não deixa de ser uma orientação. Quando você faz uma orientação no estilo, no esquema de aula, você está dando as coisas básicas, fundamentais, que o professor tem de encarar o problema. Daí pra frente, ele pode extrapolar à vontade, adaptando à área [...] você faz uma universalização da coisa. [...] além do esquema da apostila, foi criado um mecanismo de tal modo que o professor não dominasse nem a chamada e muito menos na nota. O professor está lá para mostrar seu conhecimento e simplesmente fazer com que as aulas sejam agradáveis. Só que o poder dele não existe mais, porque o poder dele é o poder da nota. $O$ poder inclusive de conhecer o aluno pelo seu nome inteiro, isso aí o professor perdeu. Ele se tornou mais, com menos poder [...] o poder que ele vai ter é exatamente o poder do verbo, dele falar, realmente transmitir a coisa"13. Os professores são submetidos a uma pesquisa mensal de opinião entre os alunos - o Ibope - que confere nota àqueles. O professor não tem autoridade para decidir por encaminhamentos sobre problemas pessoais apresentados pelos alunos, sejam eles de cunho comportamental ou relativos a orientações de estudo.

\section{O ORIENTADOR PEDAGÓGICO}

No funcionamento quotidiano do Colégio cabe salientar que a articulação do saber da apostila à animação do professor não prescinde $\mathrm{da}$ função do que se convencionou chamar de o orientador pedagógico. A conversa com alguns deles, em diferentes colégios da rede, permite depreender um mal-estar sistemático no exercício de suas atribuições, já que estes se referem à posição ocupada como bedéis de luxo, afastados da função pedagógica, mas fazendo suplência de facetas antes exercidas pelo professor: "Fazemos o suporte, a sustentação do funcionamento, mas ficamos o tempo todo no corredor colocando os alunos para dentro da sala" ${ }^{14}$. O orientador pedagógico é também intermediário das queixas do professor em relação aos alunos: "O professor que tem mais experiência ou mais carisma tem liderança e funciona mesmo como educador, mas, em geral, qualquer problema de comportamento que o professor perceba, ele retira o aluno da sala e deixa para a gente cuidar. Os professores se dirigem a nós como se fôssemos um manual de informações do tipo: qual o tempo da prova? $\mathrm{O}$ alu- 
no pode sair quando terminar?"15; "O professor também recorre a nós para reclamar: não consigo dar aula naquela sala, os alunos não me acatam"16, "Os professores se queixam de alunos pelo comportamento na sala e se o aluno não melhora eles acham que foi nossa orientação que não funcionou"17; "Nós somos muito mais presentes na vida do aluno que qualquer professor, mas nossa função é de disciplinar o funcionamento do colégio e não atender pedagogicamente. Eu queria fazer um grupo para orientar estudos, mas isso não pode"18; "O aluno nos pergunta como faz para fazer recuperação, tirar dúvidas do funcionamento, dos locais aos quais ele tem que se dirigir" 19 .

Outra função exercida é orientar e repreender o aluno em relação às normas disciplinares da escola: "Nossa função é dar suspensão, advertência, falar com o pai e a mãe, decidir se o aluno pode sair no meio da aula [...] Tenho que ensinar o aluno a tirar a média de notas para ele poder freqüentar atividades extraordinárias, que só faz quem tem nota acima de sete [...] Eu dou orientações para quem chega com perguntas do tipo: perdi a prova, como faço para recuperar?"20.

Ressalta-se ainda a função de acolhimento do aluno e de amortecimento das tensões entre aluno e professor: "Somos um pouco mães, bedéis ou madrastas. Temos de apoiar e ajudar os alunos que estão deprimidos, resolver se o professor foi grosseiro ao contar uma piada para facilitar a aprendizagem, se ele usou termos inadequados, se ele agrediu ou se ele brincou [...] Muitas vezes os alunos nos fazem de confidentes, e quando temos de dar uma suspensão eles supõem que somos falsas, que fingíamos ser amigas [...] Tenho que dar lição de moral, exercer liderança, ser mandona ou carrasca, exige tempo para aprender a função. Eu só não sou orientadora pedagógica" 21 .

$\mathrm{O}$ orientador, enfim, faz função de controle da responsabilidade que falta ao aluno: "Aqui tudo tem o mesmo controle que em qualquer colégio. Dizem que tem mais liberdade. Eu não acho. $\mathrm{O}$ aluno entra mais cedo na adolescência e sai mais tarde, porque o controle é muito grande e acaba não the dando nenhuma responsabilidade [...] Como a gente fica controlando tudo, ele é desresponsabilizado. Mas para mim o pior é que eu sou orientadora pedagógica, mas nem participo do planejamento pedagógico da escola [...] Eu acho que tinha de orientar sobre droga, mas esse assunto é proibido aqui. Quando estoura, o aluno é suspenso e pronto. Não tem brecha para falar disso aqui" 22 .

Enfim, qualificando os professores como funcionários da apostila, alguns orientadores apontam que os professores podem ser classificados a partir do equacionamento da relação tempo de aula/ 
conteúdo a transmitir: os que terminam a matéria antes da hora e, achando ridículo dar mais atividades do que o previsto, solicitam à orientadora que faça alguma atividade para segurar os alunos na sala até o fim do tempo de aula; e os que não conseguem dar a matéria, que acabam sendo obrigados a dar aulas extras. Os orientadores também classificam os alunos em dois grupos, em função de sua performance variável, a despeito de terem os mesmos professores, o mesmo material e a mesma prova: os ńtimos, que conseguem formular suas dúvidas e chegam até o plantão de dúvidas; e os péssimos, que não sabem fazer o exercício quando a formulação deste é alterada, mas que conseguem passar, já que o conteúdo das provas vai sendo aliviado no decorrer das várias chances de recuperação oferecidas pelo colégio.

\section{PARA CONCLUIR ${ }^{23}$}

$\mathrm{Na}$ perspectiva de equacionar a relação de oposição equivalente entre a pedagogia psicologizante e a pedagogia alienante, interessa notar que o recurso às várias correntes psicológicas produziu, nessas duas pedagogias, um investimento maciço na individualidade dos alunos. Tal enfoque obturou a especificidade da problematização da pedagogia em função da configuração de condições ideais de aprendizagem.

Assim, no caso da dita pedagogia psicologizante, a problematização da pedagogia foi relegada em função das condições orgânicas ou psíquicas dos alunos para aprender, bem como de suas famílias. Nessas situações, o mal-estar na aprendizagem tornou os alunos alvo dos especialistas, e não mais da escola. O controle da individualidade do aluno e de suas relações familiares estabelece, numa interface entre o público e o privado, um sistema de regulações que normatiza o aluno padrão. Nesse caso, o recurso à psicologia permite à pedagogia a imposição de normas aos alunos e a seus pais, decidindo qual aluno pode ser educado pela escola e qual deve ser excluído. Assim, na psicologização do aluno, o problema deixa de ser o método pedagógico e passa a ser a insuficiência do aluno.

Por sua vez, no caso da pedagogia alienante, a exposição do aluno à instrução programada também faz obstáculo à problematização pedagógica das vicissitudes da relação de aprendizagem. Aqui, não se trata de um sujeito aprender, mas de estabelecer condições ideais para um indivíduo qualquer incorporar e adquirir saber. Dessa perspectiva, basta ao aluno apassivar-se à instrução, seguindo os passos do condicionamento e $\mathrm{da}$ fixação gradual.

Nos dois casos, observa-se um distanciamento e, por que não dizer, uma desistência da pedagogia como disciplina, pelo recurso à psicologia em suas vertentes organicista, desenvolvimentista ou comportamental.

Além dessa desistência pedagógica, o breve estudo de caso relatado talvez possa permitir avançar um pouco na análise dessa configuração específica. Pudemos observar a condição de fragmentação do saber a 
partir do deslizamento de funções e de posições dentro de uma escola. $\mathrm{O}$ professor oferece sua imagem corporal e torna-se ator que encarna uma cena de transmissão do conhecimento, enquanto o orientador pedagógico e a apostila fazem suas demais funções. Essa implosão da referência subjetiva do saber, destituída e dissolvida naquele que representa a cena da transmissão, permite a ampliação do número de alunos por classe, mas exige sistemas extraclasse, para fazer suplência à autoridade do professor nos corredores, por meio dos orientadores pedagógicos e das atividades oferecidas aos alunos que se destacam do método (desta vez aqueles que destoam da média por manifestarem maiores condições de aprendizagem do que o previsto).

Assim, nas circunstâncias atuais de declínio da função paterna, os sujeitos não têm garantias de partiIhar objetos simbólicos. $O$ estatuto de valor dos objetos é definido anonimamente, e, portanto, o sujeito não tem parâmetros de tradição, de cultura ou de lei, para estabelecer equivalências ${ }^{24}$. Tal situação atinge diretamente a escola, encurralando as perspectivas pedagógicas que anteriormente exerciam uma função paterna ao transmitir o saber por meio do professor. Assim, podemos constatar, de um lado, a psicologização da escola, que estende a função do Outro maternante, cuja plenitude do saber sobre os alunos submete o saber dos pais a sobredeterminações de condutas quando as manifestações de seus filhos interrogam as condições do método pedagógico. Por outro lado, temos a alienação, que promete for- necer aos alunos o domínio sobre a incógnita que, no futuro, teria valor na cultura para representar os sujeitos, de modo que eles possam ser reconhecidos e privilegiados. Nesse caso, escotomizando a função paterna exercida pelo professor, esfacelam a série simbólica da representação do sujeito no campo do saber, com a qual o sujeito referencia a medida dos seus valores. Fragmentando a função paterna, produz-se um campo do imaginário de autonomia, e não um saber. Por isso essa pedagogia alienante funciona com certa eficácia, porque é totalmente simétrica, não interroga o saber. Com a pulverização da referência ao professor, o sujeito se mimetiza sustentado pela identificação, ponto a ponto, aos fragmentos de conhecimento. Sem lugar a partir do qual interrogar, o aluno é lançado numa inconsistência que o obriga a identificar-se com cada pequena parte. Por isso, o professor não deve ter relações pessoais com os alunos. Sua função passa a ser permitir a identificação do aluno a equações vazias, que não contêm um saber, já que não permitem uma posição de exterioridade a partir da qual ele possa interrogar o conhecimento, mas uma fórmula dada em um código imperativo que o aluno deve, apenas, aprender a reproduzir e a aplicar. Por isso, as regras mnemotécnicas têm vigência plena; por isso, a habilidade do professor é fisgar a atenção do aluno na composição de uma cena teatral. Nessa perspectiva, os alunos avaliam, do professor, a capacidade de oferecer recursos com os quais possam identificarse imediatamente. A função das ima- 
gens, permitindo ilusões gestálticas de completude, impedem o fomentar da interrogação sobre o conhecimento. Só resta ao pedagogo ficar nos corredores, já que não há compatibilidade entre essa prática e as interrogações da pedagogia sobre as vicissitudes do aprender.

Não é difícil notar que esse discurso promete a autonomia do sujeito à custa de aliená-lo à condição de aplicador de um instrumento - o conhecimento - sobre o qual nada quer saber. Assim, em vez de os temas adquiridos fazerem cadeia, constituindo um valor definido sintaticamente, eles estão descarrilados. Cada tema adquirido vale por si mesmo, não tem referência, não representa nada. Um valor sustentado imaginariamente, que tenta produzir uma descontinuidade no Real, passando a auto-referir-se, sem simbolizar outra coisa que não a si mesmo. Enfim, esse sistema metodológico de futuro mata a pedagogia, por considerar-se à margem da ordem simbólica. Os antigos professores, tornam-se livros vivos, perdendo seu caráter simbólico e sustentando-se da perpetuação de sua consistência imaginária.

REFERÊNCIAS BIBLIOGRÁFICAS

Calligaris, C. (1996). "Screenagers" encaram o caos. Folha de S. Paulo, 6/10.

Di Genio, J. C. (1987). A magia do cotidiano. Afinal, $3 / 11$.

Guimarāes, M. L. de A. (1996). O tempo e o espaço da alegria na escola: falas e memórias. Dissertação de Mestrado, 
Universidade Paulista (Unip), São Paulo, SP, mimeo.

Oyama, T. \& Manso, B. (1999). O dono do ensino. Veja, ne 1613, 1"/9.

Vorcaro, A. e cols. (1993). Escola do mar: interface educação-ecologia. São Paulo, SP: Cered-Fapesp.

NOTAS

1 O artigo "Screenagers' encaram o caos", publicado no caderno "Mais" da Folha de S. Paulo, em 6/10/96, foi escrito pelo psicanalista Contardo Calligaris, comentando - livro Playing the future, de Douglas Rushkoff, que saiu pela Editora Harper Collins, de Nova York, em 1996.

2 A esse respeito, conferir com artigos so. bre o Programa Objetivo de Incentivo ao Talento (Poit), divulgados no Brasil e no exterior; e também Vorcato e cols. (1993) e Guimarães (1996).

3 Entrevista com um professor.

4 Entrevista com um professor.

5 Entrevista com um professor.

6 Entrevista com um professor.

7 Entrevista com um professor.

8 Entrevista com um professor.

9 Entrevista com um professor.

10 Entrevista com um professor.

11 Entrevista com um professor.

12 Entrevista com um professor.

13 Entrevista com um professor.

14 Entrevista com um orientador pedagógico.

15 Entrevista com um orientador pedagógico.
16 Entrevista com um orientador pedagógico.

17 Entrevista com um orientador pedagógico.

18 Entrevista com um orientador pedagógico.

19 Entrevista com um orientador pedagógico.

20 Entrevista com um orientador pedagógico.

21 Entrevista com um orientador pedagógico.

22 Entrevista com um orientador pedagógico.

23 Agradeço especialmente a Alfredo Jerusalinsky e a Daniel Revah, que discutiram comigo muitas das conclusões deste trabalho.

24 Como diz Alfredo Jerusalinsky, em seminário na Derdic da PUC-SP, em novembro de 2000 .

Recebido em novembro/2000. 